\title{
PARAMETERS COMPARSION OF LEADS DETECTION IN ARCTIC SEA ICE USING CRYOSAT-2 WAVEFORM DATA
}

\author{
Jiaxing $\mathrm{Li}^{1}$, Shengkai Zhang ${ }^{1, *}$, Feng Xiao ${ }^{1, *}$, Chaohui Zhu ${ }^{1}$, Yu zhang ${ }^{1}$, Tingting Zhu $^{2}$, Lexian Yuan ${ }^{1}$ \\ ${ }^{1}$ Chinese Antarctic Center of Surveying and Mapping, Wuhan University, Wuhan 430079, China - (listening, zskai, shaw89, \\ chzhu, yuzhang_spl, yuanlexian)@whu.edu.cn \\ ${ }^{2}$ State Key Laboratory of Information Engineering in Surveying, Mapping and Remote Sensing(LIESMARS), Wuhan University, \\ Wuhan 430079, China-530409689@qq.com
}

KEY WORDS: Arctic, Sea ice, Lead, Satellite altimetry

\begin{abstract}
:
Leads are only a small part of the polar sea ice structure, but they play a dominant role on the turbulence exchange between the ocean and the atmosphere, they are also important factors about sea ice thickness inversion. Since the early 2000s, Satellite altimetry has been applied to monitor the Arctic sea ice thickness, Satellite altimetry data can be used to distinguish leads and sea ice. In this paper, four parameters including Pulse peakiness (PP), stack standard deviation (SSD), stack kurtosis (SKU) and stack skewness (SSK) are extracted from CryoSat-2 satellite altimetry waveform data. The four parameters are combined into five combinations (PP, PP\&SSD, PP\&SSD\&SKU, PP\&SSD\&SSK, PP\&SSD\&SSK\&SKU) with constrain conditions to detect the leads. The results of the five methods are compared with MODIS (moderate-resolution imagining spectroradiometer) images and show that, the combination of PP\&SSD is better than the single PP, the rest of combinations are the same as the combination of PP\&SSD. It turns out, there is no promotion when we add SSK and SKU, successively or simultaneously.
\end{abstract}

\section{INTRODUCTION}

Sea ice affects the exchange of heat, energy, mass, and momentum between the atmosphere and ocean, is an important component and indicator of changes in the global climate system. In recent years, Arctic sea ice has been very active, is considered an important factor in the global climate change process. The leads must be firstly identified to estimate sea surface height ( $\mathrm{SSH})$ and sea ice thickness. While the leads are usually covered by thin ice, resulting in misestimating $\mathrm{SSH}$, and inversing the sea ice inaccurately. It's important to find a precise method in detecting leads.

In 1969, the concept of satellite altimetry was first proposed by American geodesist Kouka at the solid earth and Ocean Physics Conference held by Williamstown. With the continuous enhancement of remote sensing technology for satellite remote sensing, the application of satellite altimetry technology is becoming more and more extensive. Since the early 2000s, Satellite altimetry has been applied to monitor the Arctic sea ice thickness, Satellite altimetry data can be used to distinguish leads from sea ice. In April 2010, CryoSat-2 was launched by the European Space Agency (ESA), the orbital inclination of CryoSat- 2 of $92^{\circ}$ provides coverage to a latitude of $88^{\circ} \mathrm{N}$ for the first time, give a certain supplement to the blank area of the previous satellite measurement (ESA, UCL., 2013). Xiao combine CryoSat-2 altimetry data and Ground elevation data during the Antarctic winter in 2013 and 2014, establish the 200 $\mathrm{m}$ resolution DEM of Larsemann Hills East Antarctica, the accuracy is better than Bamber $1 \mathrm{~km}$ DEM, ICESat DEM, RAMPv2 DEM and BEDMAP 2 (Xiao et al., 2017). In this article, the difference of the waveform parameters between leads and sea ice is discriminated, which can be used to estimate the freeboard of the sea ice (Wang et al., 2015). The pattern of ice thickness from CryoSat-2 is similar to data from Pan-Arctic Ice-Ocean Modelling and Assimilation system (PIOMAS) during winter 2011/12 with a similar winter growth curve for total ice volume
(Laxon et al., 2013). Sea ice thickness changes of Arctic sea ice in different periods were estimated using ICESat and CryoSat-2 data and the results from CryoSat-2 matched better with results from the AVHRR (Advanced Very High Resolution Radiometer) Polar Pathfinder-extended (APP-x) data than ICESat (Wang et al., 2016). The leads are distinguished using the SSD parameters of the waveform data from the CryoSat-2 satellite, the condition of SSD $<4$ are used to detect the leads (Ricker et al., 2014). Futhermore, Laxon (2013) continue to add other conditions (PP > $18 \&$ SSD $<4)$ to detect the leads. However, there is still no accurate estimation in the leads detection. Four parameters from CryoSat-2 altimetry data are chosen to distinguish the leads (Wernecke and Kaleschke., 2015). After comparing the results with MODIS images, it turns out it's best to distinguish between the leads and sea ice with the maximum parameter. ESA (2014) give the equations of parameters and Lee (2016) use the equations of SSD, SKU, SSK, PP and the value range of sea ice, leads and sea water corresponding to different parameters. Two other methods are proposed, See 5.0 decision trees and random forest, the accuracy of the two is pretty high. The results compared with MODIS, they get enough accurate data of the leads, and sea ice thickness of the Arctic sea ice has been obtained successfully.

Simple thresholding methods might not perfectly distinguish leads from ice floes because parameters, such as PP, SSD, SSK, SKU and backscatter sigma- 0 typically contain aliasing between leads and ice floes, which can result in large errors and uncertainties in sea ice thickness estimates. In this paper, four parameters from L1B waveform data of CryosSat-2 satellite are extracted, according to Laxon (2013) and Lee (2016), five combinations (PP, PP\&SSD, PP\&SSD\&SKU, PP\&SSD\&SSK, PP\&SSD\&SKU\&SSK) are proposed to detect the leads, and the results are combined with MODIS images.

\section{DATA SOURCE}




\subsection{Data}

2.1.1 CryoSat-2: CryoSat-2 was launched in April 2010 and carried the space-borne Synthetic Aperture Interferometric Radar Altimeter (SIRAL) developed by the ESA, SIRAL can satisfy the requirements of the observation of ice shelves and sea ice. (Drinkwater et al., 2003) The mission of CryoSat-2 is to detect the changing trend of the cryosphere, and the most significant mission is to verify the reduction of Arctic sea ice and the contribution of the Antarctic and Greenland to the global sea level rise. It has three operation modes: Low Resolution Mode (LRM), Synthetic Aperture Radar (SAR) and SAR Interferometry (SARIn). LRM is mainly used to measure the land of the polar regions and the relative flat ice-covered areas on the ocean. SAR is mainly used to measure floating sea ice and ice sheet, and is capable to measure the thickness of sea ice. SARIn is the most advanced mode of CryoSat-2. It is mainly used to measure the edge of ice sheet and Alpine glacier. The mode can accurately measure the location of tilted surface, and it can be used to study areas with large undulating topography, such as Antarctic continent or Greenland. Data collected in SAR and SIN modes are optimized to estimate sea ice thickness because the sensor in the operation modes can measure sea ice characteristics with high spatial resolution comparable to the size of leads. CryoSat-2 data has a high coverage range because of the narrow orbital space. Detailed specifications of CryoSat-2 are presented in Table 1, where the PRF means Pulse Repetition Frequency.

\begin{tabular}{cc}
\hline & CryoSat- 2 \\
\hline Center frequency & $13.575 \mathrm{Ghz}$ \\
Band width & $320 \mathrm{MHz}$ \\
PRF $\quad 1.97 \mathrm{kHz}(\mathrm{LRM}) / 18.181 \mathrm{kHz}(\mathrm{SAR}$ and SIN) \\
Pulse duration & $44.8 \mathrm{~ms}$ \\
Samples in echo & 128(LRM AND SAR)/512(SIN) \\
Antenna footprint & $0.29 \mathrm{~km}$ \\
Range bin sample & $0.4684(\mathrm{LRM}) / 0.2342(\mathrm{SAR}$ and SIN) \\
\hline
\end{tabular}

Table 1. Detailed specifications of CryoSat-2

The CryoSat-2 satellite L1B waveform data we used in the experiment, is from SAR. This enables the satellite to effectively distinguish the high backscatter surface of the narrow leads and the surface of the low backscatter ice floe. Four parameters PP, SSD, SKU, SSK which can represent surface features are extracted to distinguish the leads from sea ice.

-PP has been established by Laxon (1994b) and is defined as the MAX (the highest recorded power of the calibrated waveform in Watts) divided by the accumulated power $\left(p_{i}\right)$ of all bins constituting the waveform. which is the same definition as used by Armitage and Davidson (2014), while the values of Laxon (2013) are divided by 100 and those of Ricker (2014) by 128 for consistency.

$$
\mathrm{PP}=\frac{\mathrm{k} \times \mathrm{MAX}}{\sum_{i=1}^{n} p_{i}}
$$

where $\mathrm{k}=1$

$$
\mathrm{n}=128(\mathrm{SAR}) \text { and } 512(\mathrm{SARIn})
$$

- SSD is the standard deviation (SD) of the mentioned Gaussian distribution of the energy as function of beam number (i.e., incidence angle).

$$
\mathrm{SSD}=\frac{1}{2} \frac{\sum_{i=1}^{N} S P^{2}(i) \sum_{i=1}^{N} S P^{2}(i)}{\sum_{i=1}^{N} S P^{4}(i)}
$$

where SP stands for integrated stacked power that is not obtainable in the L1B data. The integrated stacked power is the summation of each single look echo power.

- SKU measures the peakedness of the range stacked power distribution.

$$
\mathrm{SKU}=\frac{\frac{1}{N} \sum_{i=1}^{N}(S P(i)-\mu)^{4}}{\left[\frac{1}{N-1} \sum_{i=1}^{N}(S P(i)-\mu)^{2}\right]^{3}}-3
$$

where $\quad \mu=\frac{1}{\mathrm{~N}} \sum_{i=1}^{N} S P(i)$

- SSK measures the asymmetry of the range stacked power distribution.

$$
\operatorname{SSK}=\frac{\frac{1}{N} \sum_{i=1}^{N}(S P(i)-\mu)^{3}}{\left[\frac{1}{N-1} \sum_{i=1}^{N}(S P(i)-\mu)^{2}\right]^{2 / 3}}
$$

2.1.2 MODIS: MODIS is onboard the Terra and Aqua satellites, which were launched in 1999 and 2002, respectively. Covering the earth surface every 1 to 2 days and having 36 spectral bands from $0.4-14.4 \mu \mathrm{m}$ make MODIS a vital role in observing the Earth's environment. It's an ideal way to separate leads and ice floes using MODIS images because of the different albedo between the leads and ice floes. MOD02QKM, one of the MODIS L1B products, is a calibrated and geolocated dataset with two bands $(0.645 \mu \mathrm{m}$ and $0.858 \mu \mathrm{m})$ at a $250-\mathrm{m}$ ground sample distance.

On MODIS images, we interpret the dark areas with sharp edges and linear shapes into the leads. The data of the Cryosat-2 satellite measurements that fall on the dark area are also the data of the leads.

\subsection{Experiment Area}

Our experiment Area is in the Arctic Beaufort Sea (from $136^{\circ} \mathrm{W}$ to $137^{\circ} \mathrm{W}$, from $71^{\circ} \mathrm{N}$ to $73^{\circ} \mathrm{N}$ ). Based on the area, we select an appropriate satellite path over the sea. Figure 1 shows the location of the path over the Beaufort sea.

The CryoSat-2 data selected for experiment is on March 30, 2015. The MODIS data with great accuracy which can distinguish the leads and sea ice clearly are selected at the same area and on the same day. The time difference for CryoSat-2 and MODIS data is less than 1 hour. The path covers with the leads and sea ice. The number of the path is 1266 . We intercept a fraction of it, there are 573 points totally. 


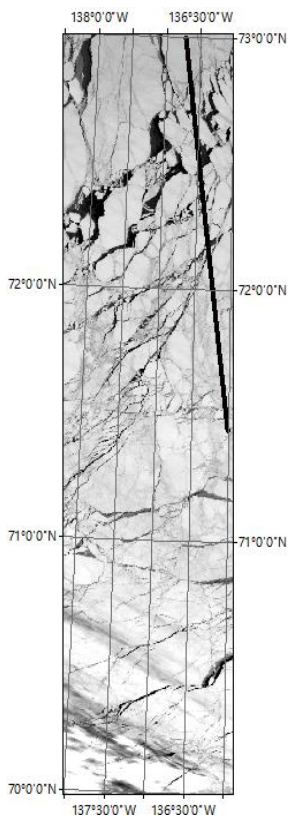

\section{DATA PROCESSING}

According to Laxon (2013), we first use the condition of PP $>18$ to distinguish leads from sea ices. Then it is distinguished by the combination of the parameters of PP $>18$ and SSD $<400$, By comparison, it can be seen that when the PP parameter is used to distinguish the leads, overestimating the number of points located on the leads, and can't accurately detect the leads. In comparison, the PP\&SSD parameters combination is more accurate to detect the leads, but errors still exist.

Then, on the basis of the above conditions, the parameters SKU, SSK are added successively. According to Lee (2016), the constrain conditions are SKU $>80$, SSK $>9$, respectively.

Finally, on the basis of the combination of PP\&SSD parameters, SKU and SSK are added simultaneously. The constrain conditions remain unchanged.

All the results are exhibited in the Figure 2.

Figure 1. experiments Area in the Arctic Beaufort Sea
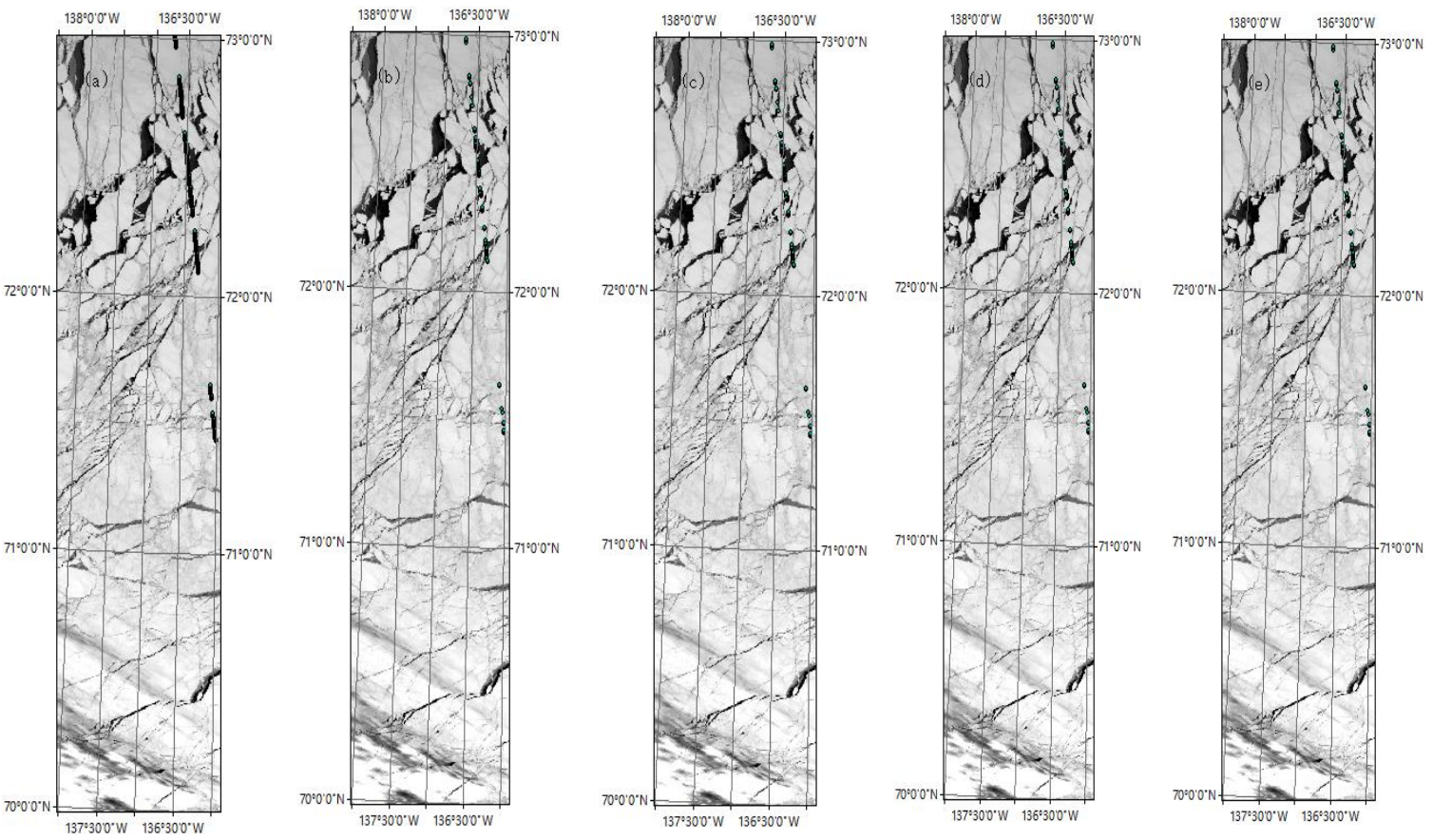

Figure 2. The CryoSat-2 samples have been classified as lead and ice manually by PP (a), PP\&SSD (b), PP\&SSD\&SKU (c) PP\&SSD\&SSK (d), PP\&SSD\&SKU\&SSK (e)

\section{CONCLUSION}

Arctic sea ice freeboard and sea ice thickness play an important role in polar sea ice research. It is very important to detect the leads accurately according to the cryosat-2 satellite altimetry data. Compared with the existing detection methods, there is no obvious promotion.

The method of detecting the leads based on the parameters of the waveform of the altimetry satellite data has been proposed. Four parameters including PP, SSD, SSK and SKU are selected. SSK has not been used in previous studies, as well as the combinations of these parameters. Firstly, we use PP and the combination of PP\&SSD parameters to distinguish leads from ices. Our study shows the PP\&SSD parameters combination method provide a more accurate result than the PP method. The biases are still existing because of the unsynchronized satellite path for the two different satellite (MODIS and CryoSat-2) and inaccurate constrain conditions. Next, we add other parameters to complete the constrain conditions. However, the results detected by other combinations of the parameters did not reach our expectations. They don't have any promotion on the previous method.

\section{ACKNOWLEDGEMENTS}

This work is supported by the National Key Research and Development Program of China (2017YFA0603104), National 
Natural Science Foundation of China (41730102, 41531069), Independent Scientific Research Program for Cross-disciplinary of Wuhan University (2042017kf0209).

\section{REFERENCES}

Armitage, T. W. and Davidson, M. W., 2014. Using the interferometric capabilities of the ESA CryoSat-2 mission to improve the accuracy of sea ice freeboard retrievals, IEEE T. Geosci. Remote, 52, pp. 529-536.

Drinkwater, M.R., Francis, R., Ratier, G., et al., 2004. The European Space Agency's earth explorer mission CryoSat: measuring variability in the cryosphere. Annals of Glaciology, 39(1), pp. 313-320.

European Space Agency (ESA), University College London (UCL)., 2013. CryoSat Product Handbook, ESRIN-ESA and Mullard Space Science Laboratory-University College London: London, UK.

European Space Agency (ESA)., 2014. Beam Behavior Parameters in CryoSat Levellb Products; ESA: Paris, France.

Laxon, S.W., Giles, K.A., Ridout, A.L. et al, 2013. CryoSat-2 estimates of Arctic sea ice thickness and volume GEOPHYSICAL RESEARCH LETTERS, 40, pp. 732-737.

Lee, S., Im, J., Kim, J., et al., 2016. Arctic Sea Ice Thickness Estimation from CryoSat-2 Satellite Data Using Machine Learning-Based Lead Detection. Remote Sensing, 8(9), pp. 698.

Laxon, S.W., 1994b. Sea ice extent mapping using the ERS-1 radar altimeter, EARSeL Adv. Remote Sens., 3, pp. 112-116.

Ricker, R., Hendricks, S., Helm, V., et al., 2014. Sensitivity of CryoSat-2 Arctic sea-ice freeboard and thickness on radarwaveform interpretation. Cryosphere, 8(4), pp. 1607-1622.

Wang, L.W., Jin, T.Y., Zhang, S.J., Li, D.W., 2015. Cryosat-2 Satellite Sea Ice Area Waveform Recognition and Freeboard Determined. Journal of Geodesy and Geodynamics. 35(4), pp. $722-725$.

Wang, X., Key, J., Kwok, R., et al.,2016. Comparison of Arctic Sea Ice Thickness from Satellites, Aircraft, and PIOMAS Data. Remote Sensing, 8(9), pp. 713.

Wernecke, A., Kaleschke, L., 2015. Lead detection in Arctic sea ice from CryoSat-2: quality assessment, lead area fraction and width distribution. Cryosphere, 9(2), pp. 2167-2200.

Xiao, F., Li, F., Zhang, S.K., 2017. DEM Production for Larsemann Hills Combining Cryosat-2 and Ground-based Elevation. Geomatics and Information Science of Wuhan University, 42(10), pp. 1417-1422. 